\title{
HYPERTROPHY OF THE LOWER LIMBS WITH CUTANEOUS NAEVUS AND VARICOSE VEINS
}

\author{
BY \\ L. M. ROSE, B.M., M.R.C.P. \\ From the Children's Hospital, Sheffield
}

(Received for Publication, July 22, 1949)

The occasional occurrence of hypertrophy of a limb associated with cutaneous naevi or haemangiomata, together with congenital or developmental defects of the arteries and veins, has long been recognized.

In 1858 Adams described a 'singular case of Hypertrophy of the Right Lower Extremity with Superficial Cutaneous Naevus of the Same Side.' This appears to be the first description of such a condition in English.

Trélat and Monod (1869) in their treatise on unilateral hypertrophies of the limbs, recognized the association of hypertrophy of the bones of one leg with cutaneous naevi and varicosities of the veins of the affected limb. The limitation of the vascular anomalies to the abnormally long limb led them to believe that the two had a common developmental origin.

Under the title Du naevus variqueux ostéohypertrophique, Klippel and Trenaunay (1900) described a condition the main features of which were : (1) A superficial naevus of the lower limb, (2) varicosities of the veins on the same side as the naevus, (3) hypertrophy of the affected lower limb, involving the soft and bony tissues, overgrowth of the skeleton being especially prominent. It was thought possible that these anomalies had a common congenital origin.

In his classical paper, Parkes Weber (1918) described the association of congenital or developmental hypertrophy of the limbs with dilatation of the arterial and venous trunks. He collected several examples of this condition from the literature, to which the collective name of 'haemangiectatic hypertrophy' was given. This type of enlargement he differentiated from congenital trophoedema of the Nonne-Milroy-Meige type and also from that met with in simple hemihypertrophies of the limbs. In the latter, cutaneous naevi or haemangiomata are by no means uncommon, but there is no abnormality of the arteries or veins of the affected limbs.

The condition of dilatation of arteries and veins has been given the pathological appellation of ' congenital or developmental phlebarteriectasis,' of which several clinical varieties have been recognized. In the most extreme form a free anastomosis may exist between dilated arteries and veins. In a less severe form, to which the term 'genuine diffuse phlebarteriectasis' has been applied, there is no abnormal communication between the dilated arteries and veins. When the arteries are little affected, the dilatation being confined mainly to the veins, the condition is called 'genuine diffuse phlebectasis.' This last group may be considered to be one variety of congenital varicose veins in contrast to that caused by congenital obstruction in a main venous trunk. In all these types of haemangiectatic hypertrophy, cutaneous naevi or haemangiomata are commonly but not invariably present.

The condition described by Klippel and Trenaunay in which the veins alone are affected is probably best considered to be a member of the larger group of haemangiectatic hypertrophies. This syndrome appears to be closely related to, if not identical with, genuine diffuse phlebectasis or congenital varicose veins. It is interesting that in the earlier descriptions of congenital varicose veins, hypertrophy and cutaneous naevi are frequently mentioned as incidental findings (Champendal, 1900, and Besson, 1919, quoted by Lian and Alhomme, 1945).

Since the publication of Parkes Weber's paper in 1918 several examples of hypertrophy of limbs associated with vascular abnormalities have been recorded. Paterson and Wyllie (1925) described a case of hypertrophy of the bones of a limb due to a naevus. Under the title of ' haemangiectatic hypertrophy' cases have been described by Beatty (1927), Gray (1928), East (1932), Blumgart and Ernstene (1932), and Reichenheim (1943). Gougerot and Filliol (1929) described a case under the title Naevus variqueux ostéohypertrophique de Klippel ou Hémangiectasie de Parkes Weber. They also collected six earlier cases from the French literature. 
Downing (1933) recorded a case described as Naevus flammeus et varicosus: hemihypertrophy. Freund (1936) collected 15 cases of diffuse genuine phlebectasia from the literature and described a further one. Examples of congenital varicose veins associated with limb enlargement have been described by Servelle $(1945 ; 1947)$, Lian and Alhomme (1945). The latter give the subsidiary title of Klippel-Trenaunay syndrome to their paper. Louis-Bar and Legros (1946) described three cases of 'partial hypertrophy with angioma (KlippelTrenaunay syndrome)'. Van Bogaert and Kegels (1947) have recorded a further case of KlippelTrenaunay syndrome. Congenital arteriovenous communications associated with hypertrophy have been described by Reid (1925), Pemberton and Saint (1928), Lewis (1930), Horton (1934), Reid and McGuire (1938), Ward and Horton (1940).

The present case approximates to that form of haemangiectatic hypertrophy in which there is minimal abnormality of the arterial system, the main vascular defects being those of the skin and the superficial veins, the syndrome accurately defined by Klippel and Trenaunay in 1900.

\section{Case History}

The patient is a boy born on December 10, 1941 . When he was seven years old he was referred to a plastic surgeon with the complaint that the right lower limb had been larger than the left since infancy and had increased in size in the past year. It was also thought that the left foot, although not so large as the right, was considerably larger than normal. Shortly afterwards he was admitted for investigation.

$\mathrm{He}$ is the only child, and was born at term. Delivery was normal (birth weight, $7 \mathrm{lb}$.).

At the age of 17 years his mother developed varicose veins of the right lower limb. During pregnancy, when 20 years old, varicose veins appeared on the left lower limb, and those of the right became more prominent. Since that time she has had repeated injections of sclerosing substances into the veins without much relief. The mother has no cutaneous naevi, and there is no asymmetry or enlargement of the limbs. There is no history of a similar condition in other members of the family. The parents are not blood relations.

At birth it was seen that the right lower limb was longer than the left. There was no apparent difference in girth of the lower limbs at this time. An extensive birthmark was present on the right thigh, the right side of the abdomen, and on both sides of the chest. A soft swelling was noticed on the lower part of the right anterior chest wall. A more extensive swelling of a similarly soft consistency was seen on the left side of the abdominal wall.

In the neonatal period and in early childhood his health was good. He had measles and whooping cough when he was four years of age. Mental development has been normal. He went to school when five years old and is in a class of children of his own age. Since he first wore shoes he has always had to have a larger shoe for the right foot than the left. Until he was five years old, in spite of the greater length of the right leg, he suffered no disability and there were no subjective complaints. At this time he began to have attacks of dull, aching pain in the right calf and thigh which recurred every two or three months. The pain was precipitated by over-exertion during the day, or occurred when he was warm in bed. It would last for several hours and was relieved by rest or locally applied heat. Occasionally the right lower limb felt hot and throbbed, at which time the birthmark on the thigh became a deeper colour. In the past two years the attacks of pain have become more frequent and at present occur every three of four weeks. In the past year the right lower limb has increased in girth. During this time prominent veins have appeared on the right thigh, below the right knee and on the front of the right ankle. Coincident with the attacks of pain the veins have been swollen and tender. The swellings on the chest and abdomen have not increased in size recently, but another similar swelling was noticed a year ago in the right groin. In spite of the repeated pains in the leg the patient has not been greatly incapacitated. He leads a normal life at school, is able to run and plays games.

No asymmetry or increase in size has been observed in the upper limbs. The birthmark has not become more extensive since infancy.

Clinical Examination. The patient was a thin, agile boy of good intelligence. Height, $51 \frac{1}{2}$ in. Weight, $71 \mathrm{lb}$. The right lower limb was appreciably larger than the left both in length and in girth, with considerable obliteration of the bony outline of the right knee. Both feet were abnormally large, the right more than the left. The second toe of the right foot was especially prominent. The increase in length of the right lower limb appeared to be equally distributed between the thigh and leg. The right buttock was enlarged. There was no scoliosis, but the right side of the pelvis was tilted upwards and there was a lumbo-dorsal lordosis. The upper limbs were of equal size. There was no asymmetry of the face or thorax. The musculature of the upper part of the body was poorly developed. The abdomen was protuberant, the left side more than the right.

An extensive naevus covered the greater part of the right lower limb, and part of the anterior abdominal wall, chest, and back. It was not raised above the skin surface and was of the naevus flammeus or 'port wine stain ' variety. In colour it varied from a violet-pink on the right lower limb to a light brown on the abdomen and back. The naevus occupied the lateral half of the right thigh, being defined by a line passing from the anterior superior iliac spine to the medial side of the right knee. Below the right knee the distribution was irregular. It gradually merged into normally coloured skin on the dorsum of the foot. The right buttock and posterior surface of the right thigh were wholly covered by the naevus, which in its upper part extended across the natal cleft to end in an irregular vertical line on the medial side of the left buttock. Compared with the right lower 


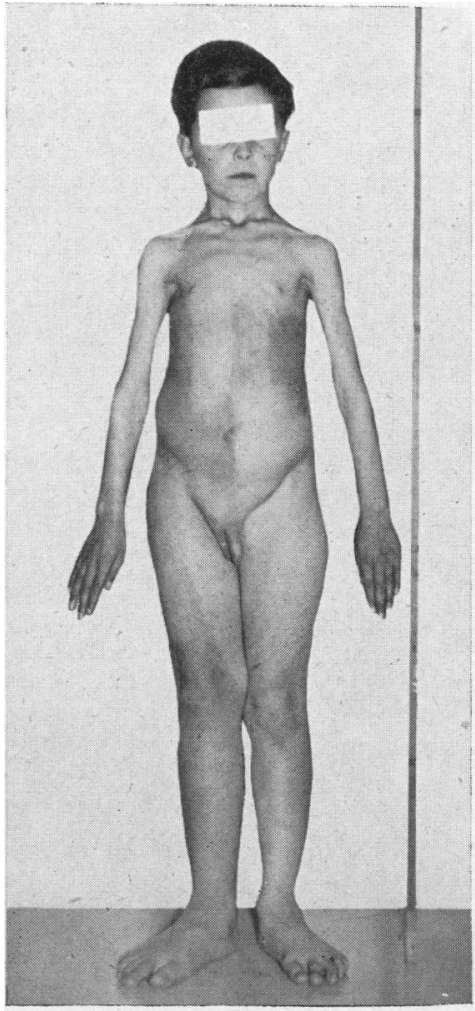

FIG. 1

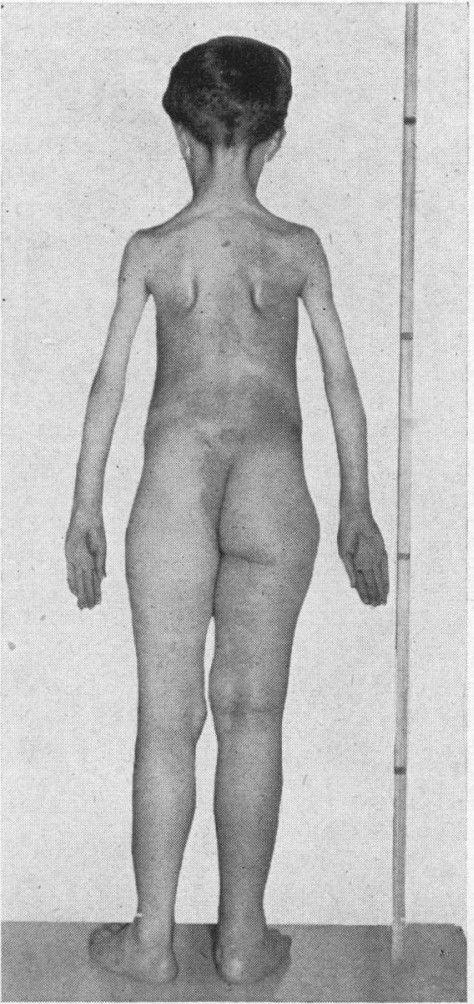

FIG. 2

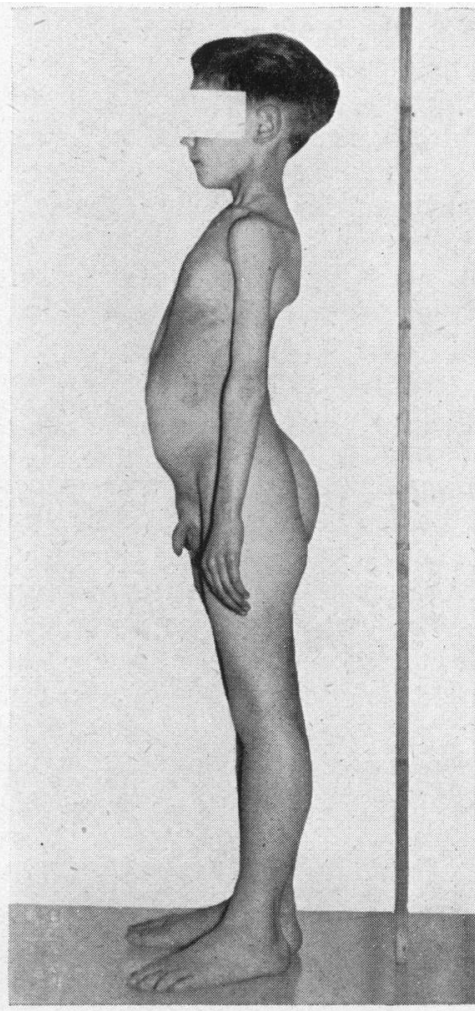

FIG. 3

Figs. 1, 2, and 3.-Different postures showing asymmetry of lower limbs and extent of naevus.

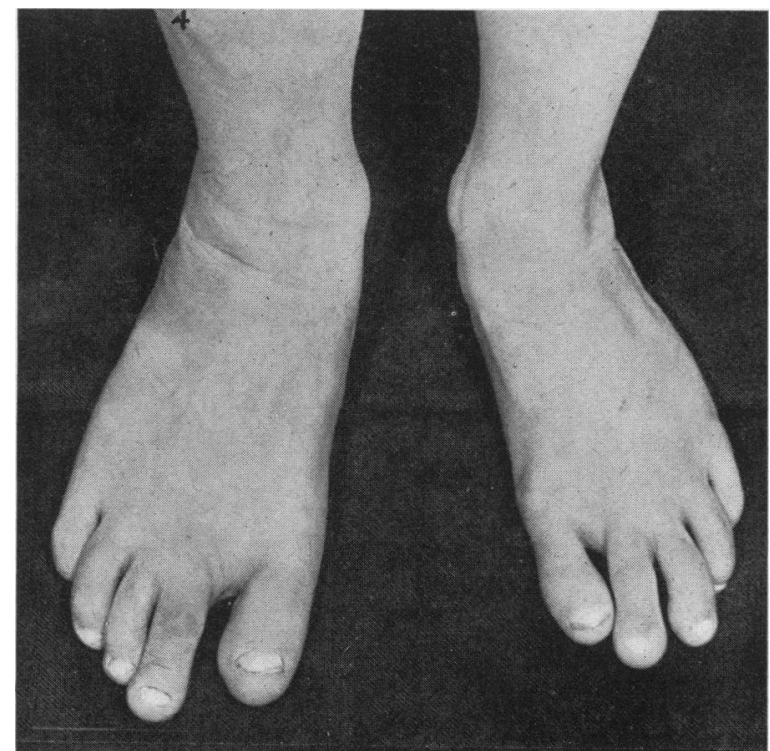

FIG. 4.-Photograph showing difference in size of feet. 
limb, the left was little affected. On the posterior surface of the left thigh there were several faint pink areas 1 to 2 in. in diameter. The naevus covered the whole lower right quadrant of the abdominal wall ending abruptly at the midline, and extending upwards on to the right side of the chest and right axilla. A large patch occupied the lower part of the left chest and loin. Anteriorly, a fainter area extended to the midline over the lower sternum and epigastrium. Irregular patches were present over most of the back from mid-scapula to the coccyx. A small deeper pigmented patch was situated over the sacrum. The skin of the upper limbs, scalp, face, neck, and scrotum was normal. When both lower limbs were cold the naevus on the right lower limb became deeper in colour and the whole limb appeared cyanotic. The colour became pinker when the limb was warmed (Figs. 1, 2, 3, 4).

Over the right lower costal cartilages there was a smooth subcutaneous mass 3 in. in diameter having the characteristics of a lipoma. A more diffuse mass of similar consistency covered most of the left side of the abdominal wall. A third lipoma was in the right spermatic cord. The skin overlying these three tumours was not involved by the naevus.

There were dilated superficial veins on the lateral side of the right thigh, below and lateral to the right knee, and on front of the ankle. Those below the knee were raised above the skin surface. There was no pulsation over the abnormal veins. After standing for several minutes the dilatation of the veins increased, but rapidly subsided when the limb was kept horizontal.

Pulsation of the femoral arteries was palpable on both sides. On the right side the popliteal and dorsalis pedis arteries could only be felt with difficulty. Those of the left limb were normal. The skin of the right lower limb was warmer to the touch than the left. Skin temperature readings revealed that the right leg was consistently 1 to $2^{\circ} \mathrm{F}$. warmer than the left.

The musculature of the right buttock and right lower limb was well developed but softer than that of the left side. Muscle power was equal on both sides. There was

Measurements of THE LimbS

\begin{tabular}{|c|c|c|}
\hline & $\begin{array}{c}\text { Right } \\
\text { (in.) }\end{array}$ & $\begin{array}{l}\text { Left } \\
\text { (in.) }\end{array}$ \\
\hline $\begin{array}{l}\text { Anterior superior iliac spine to } \\
\text { medial malleolus } \ldots \\
\begin{array}{l}\text { Anterior superior iliac spine to } \\
\text { medial epicondyle femur } \ldots\end{array} \\
\text { Medial epicondyle femur to medial } \\
\text { malleolus } \ldots\end{array}$ & $\begin{array}{l}27 \frac{1}{4} \\
15 \\
12 \frac{3}{4} \\
12 \frac{1}{4} \\
14 \frac{1}{2} \\
12 \frac{1}{4} \\
10 \\
8 \frac{1}{4}\end{array}$ & $\begin{array}{l}124 \\
11 \frac{1}{4} \\
13\end{array}$ \\
\hline
\end{tabular}

no oedema of the lower limbs. No thrills were felt and no murmurs were heard on auscultation over the lower limbs. There was no abnormality of sensation or sweating in either limb.

The pulse was regular, 90 beats per minute. The apex beat was palpable 2 in. from the midline in the fourth left interspace. There was no cardiac enlargement and the heart sounds were normal.

Blood pressure:

Right arm 108/62; left arm 110/60.

Right leg 130/80; left leg 132/80.

No abnormal signs were found in the respiratory system. There was no enlargement of the abdominal viscera.

No abnormalities were detected in the cranial nerves. The tendon reflexes were normal in the upper and lower limbs. Abdominal reflexes were present. Plantar reflexes were flexor. The optic discs and vessels were normal.

Investigations. X-ray films of the lower limbs showed that there was elongation of all bones of the right limb compared with the left. There was thickening of the cortex of the right femur and tibia (Figs. 5, 6, and 7). Films of the skull, upper limbs, spine and pelvis were normal. A radiograph of the chest showed a normal cardiac outline, no cardiac enlargement, and normal lung fields.

Arteriograms were performed on both lower limbs, $20 \mathrm{ml} .50 \%$ diodone being introduced into each femoral artery. No evidence of an abnormal arteriovenous communication was obtained in either limb. It was, however, seen that the superficial veins of the right limb were more dilated than normal.

The oxygen content of blood withdrawn from the right femoral artery and vein, and the right basilic vein was determined. The results were as follows:

\begin{tabular}{|c|c|c|c|}
\hline & & $\begin{array}{l}\text { Oxygen } \\
\text { Content } \\
\text { (vols. \%) }\end{array}$ & $\begin{array}{c}\text { Oxygen } \\
\text { Saturation } \\
(\%)\end{array}$ \\
\hline $\begin{array}{l}\text { Saturated blood .. } \\
\text { Right femoral artery } \\
\text { Right femoral vein } \\
\text { Right basilic vein .. }\end{array}$ & $\begin{array}{l}\cdots \\
\cdots \\
\cdots \\
\cdots\end{array}$ & $\begin{array}{l}20 \cdot 73 \\
17 \cdot 8 \\
13 \cdot 4 \\
15 \cdot 3\end{array}$ & $\begin{array}{l}100 \\
86 \cdot 4 \\
64 \cdot 5 \\
73 \cdot 9\end{array}$ \\
\hline
\end{tabular}

An electrocardiogram showed no abnormality.

The effect of sudden occlusion of the right and left femoral arteries on the pulse rate was observed. A sphygmomanometer cuff was applied at a pressure of $160 \mathrm{~mm}$. $\mathrm{Hg}$ to each thigh in turn, a continuous electrocardiographic record being taken before and during occlusion. There was no slowing of the heart after occlusion of each femoral artery.

The effect of occlusion of the femoral arteries on the blood pressure in the upper limbs was also observed. The upper limb pressures remained unaltered after a pressure of $160 \mathrm{~mm}$. $\mathrm{Hg}$ had been applied to each thigh in turn.

The Wassermann and Kahn reactions were negative. A blood count and urine analysis were normal. 


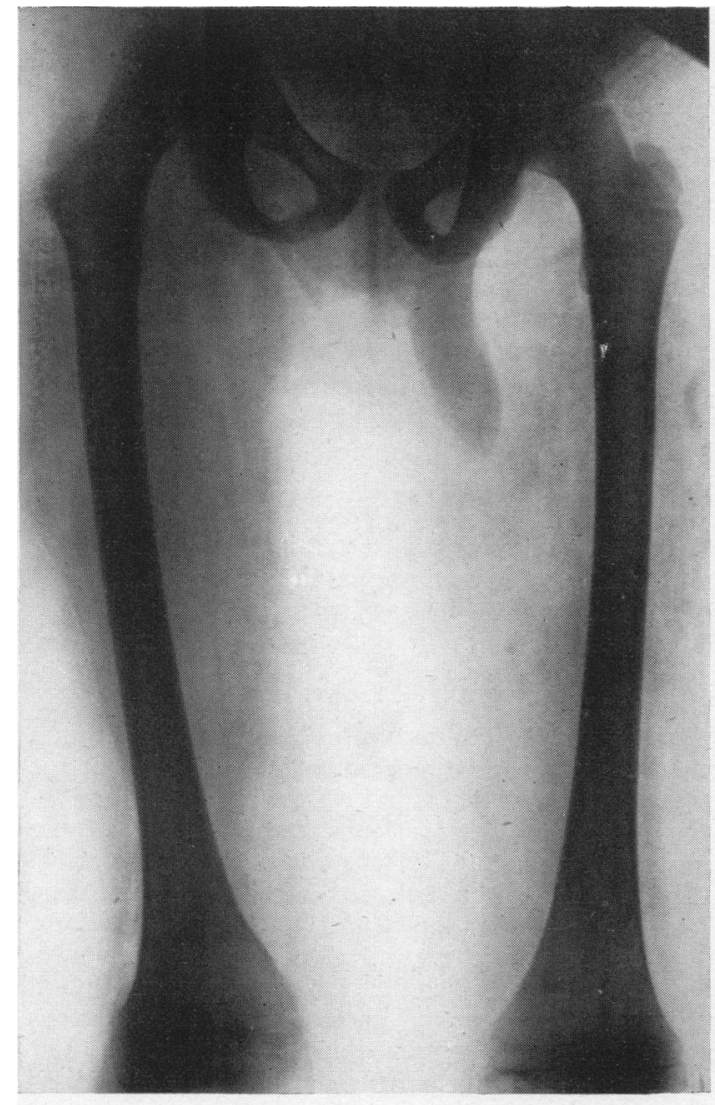

FIG. 5

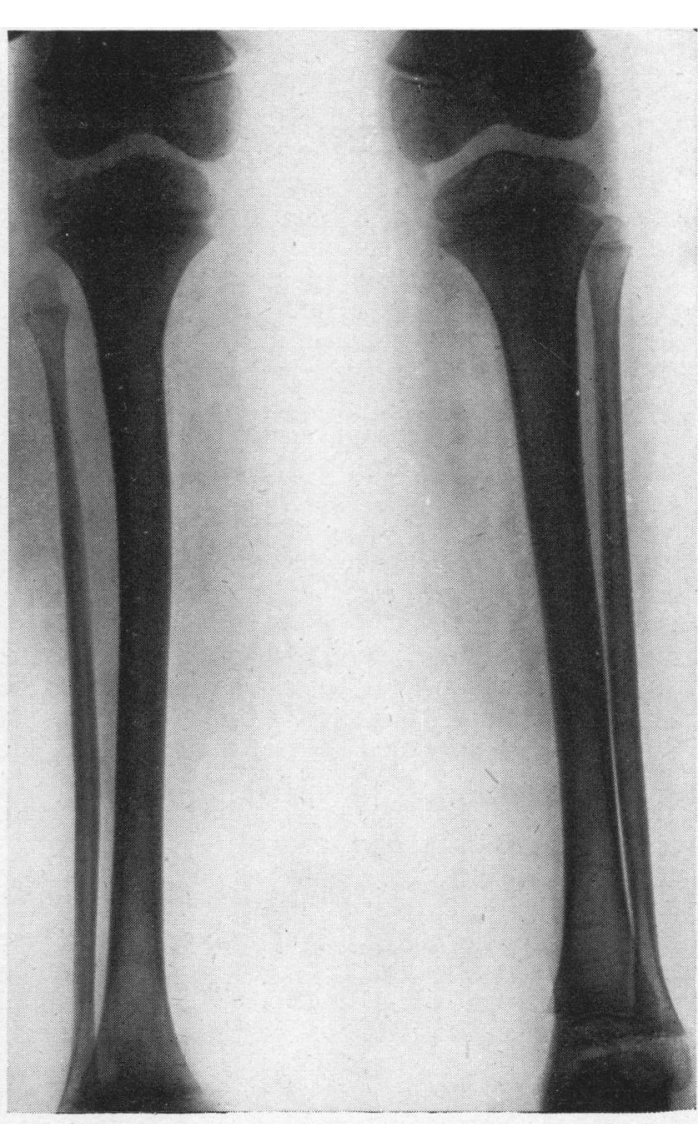

FIG. 6

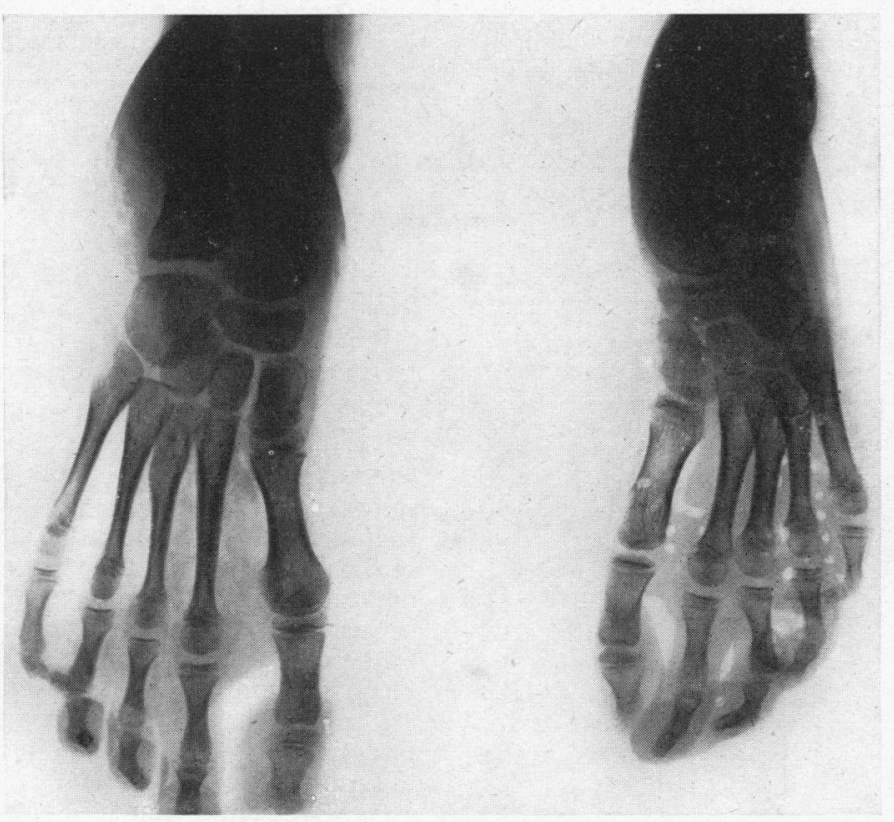

FIG. 7

FIGs. 5, 6, 7.-Radiographs of lower limbs, showing elongation of bones of right side. 


\section{Discussion}

Clinical Features. The cardinal features of haemangiectatic hypertrophy are hypertrophy of a limb, the frequent occurrence of cutaneous naevi and abnormalities of the vessels in the affected limb.

Hypertrophy. Trélat and Monod (1869) observed that most often the enlargement of the limb is generalized, there being an increase in both length and in girth. The enlargement is seen at birth or in the first few months of life, but may escape notice until the child begins to walk. In spite of the enlargement the configuration of the limb remains more or less normal, gross deformity only being seen in the rarer types where hypertrophy is partial and limited to the hand or foot. Most commonly one leg is affected, an upper limb less often. Hemihypertrophic forms in which an arm and leg on one side are enlarged have been described by Parkes Weber (1907), Cagiati (1907), Gougerot and Filliol (1929), Downing (1933), Reichenheim (1943), Lian and Alhomme (1945). In these there may also be involvement of the skull and thorax on the affected side. Crossed forms in which an arm and a leg on opposite sides of the body are enlarged appear to be very rare, as do those in which both legs are affected. An example of the latter is described by Lian and Alhomme (1945). Eventually the bones of the limb show some lengthening. Radiologically there is little change in the bone structure except for the increase in length. The cortex of the long bones may be thickened. In the later stages generalized osteoporosis may occur. Occasionally phleboliths are seen as described by Freund (1936), Ward and Horton (1940). Depending on the extent to which a lower limb is lengthened, there is a compensatory scoliosis of the vertebral column with upward tilting of the pelvis on the affected side. Lian and Alhomme (1945) describe the rare complication of dislocation of the hip on the lengthened side.

Hypertrophy of the soft tissues usually involves muscles, connective tissue, and fat. The peripheral nerves are not affected but the occasional occurrence of neurofibromatous tumours akin to the plexiform tumour of von Recklinghausen's disease has been reported (Louis-Bar and Legros, 1946). Muscular power may be increased in the hypertrophic limb but this is inconstant. Visceral enlargement has been described in the hemihypertrophic type, as in the case of Cagiati (1907), in which enlargement of the viscera on the left side of the abdomen accompanied hypertrophy of the left upper and lower limbs. When the face is involved there may also be hemihypertrophy of the tongue (Gougerot and Filliol, 1929).

Cutaneous Manifestations. The cutaneous naevus is usually of the naevus flammeus or "port-wine stain' type, which is present at birth. Occasionally small, pigmented, nodular haemangiomata may be found on the naevus or the adjacent skin. The naevus varies in colour from deep red to a faint pink or brown which may be hardly distinguishable from the normal skin. Gray (1928) described an unusual form of naevus in which pigment was present in the basal cell layer of the epithelium.

There is great variation in the size and distribution of the naevus. Adams (1858) recorded that the naevus may end abruptly at the medial line of the body, an observation which has since been frequently made. Most often the enlarged limb is affected but its occurrence in other sites has been reported. Gougerot and Filliol (1929) maintain that there is no constant correlation between the site of the naevus and the limb involved. The naevus often roughly corresponds with the distribution of the sensory nerve roots, and Lian and Alhomme (1945) remark on its resemblance in shape to the eruption of herpes zoster. The edges are usually irregular but may fade imperceptibly into normal skin.

The skin of the affected limb is usually normal in texture but may be dry and scaly, becoming atrophic or indurated in the later stages. The skin temperature is often raised over the limb, and the sweat glands may be over-active (Klippel and Trenaunay, 1900; Gougerot and Filliol, 1929). Cutaneous sensation is usually normal. Subcutaneous lipomata are a somewhat rare finding and have been reported by Friedberg (1867) and Reichenheim (1943).

Blood Vessels. The vascular defects in haemangiectatic hypertrophy vary from simple dilatations of the veins to true arteriovenous communications.

Varicose veins are common in all varieties of haemangiectatic hypertrophy. They may be present at birth, but more often develop during childhood or early adult life. The onset of puberty may coincide with an increase in their number or sometimes with their first appearance. Their presence is, however, no indication of any underlying defect of the arterial system. Clinically the varicosities resemble those occurring in later life, but the local manifestations may be more severe. Ulceration of the overlying skin is common, often to be followed by severe haemorrhage. Treatment of the varicose veins is rarely successful. Extensive ligation or excision of veins is of little effect. Lian and Alhomme (1945) mention that sclerosing agents in higher concentrations than are usual may be tried. Their effect is only palliative.

The clinical features of arteriovenous communications are often inconspicuous. Thrills and bruits over the affected limb are uncommon, in contrast to their frequent occurrence in traumatic fistulae. 
This is probable because the communication is so small. Rarely, the heart is enlarged. Ward and Horton (1940) found cardiac enlargement in only two of their 33 cases of congenital communications in children. There are some signs which may be helpful in the diagnosis of these communications. Nicoladoni (1875) and Branham (1890) observed that compression of the artery proximal to the communication may result in a decrease in pulse rate, the so-called 'bradycardiac reaction.' It is also known (McGuire, 1935) that both the systolic and diastolic blood pressures elsewhere in the body may be increased following closure of the arterial component of the fistula. Horton (1933) introduced the use of arteriography in the detection of these communications. In the same paper he drew attention to the value of estimating the oxygen saturation of the venous blood proximal to the communication. The venous blood will in such a case contain more oxygen than normal, and is evidence of the passage of arterial blood directly into the vein.

Aetiology. The presence of these various anomalies at birth is suggestive of some causative agent acting on the embryo in the early stages of its development. It is unusual for there to be evidence of any inherited factor in the production of the disease. Lian and Alhomme (1945), however, describe an example of the Klippel-Trenaunay syndrome in a young man whose father, uncle, and grandfather all had congenital varices affecting one limb. The uncle also had hypertrophy of one side of the thorax.

Louis-Bar and Legros (1946) suggest that haemangiectatic hypertrophy is an allied condition to the Sturge-Kalischer-Weber syndrome of cerebral angioma accompanied by a facial naevus. Parkes Weber (1947) considers that the latter condition and similar 'telangiectatic and angioma-like dysplasias' are caused by some ' accidental' local injury to the embryo during early intra-uterine life. Louis-Bar and Legros (1946) draw attention to other conditions in which hypertrophy of a limb may be an occasional occurrence, such as neurofibromatosis of von Recklinghausen and tuberose sclerosis. They consider that these conditions may be related to the haemangiectatic hypertrophies.

Congenital syphilis has been invoked as a cause, but the presence of positive serological reactions as in the cases of Beatty (1927) and Gougerot and Filliol (1929) appears to have been fortuitous. Increase in the local blood supply to the part has been held responsible for the hypertrophy. Klippel and Trenaunay (1900) thought that the cutaneous naevus may be responsible for this increased supply, but they recognized that the naevus was not invariably present on the enlarged limb. In the case of experimental arteriovenous communications there is some evidence that an increase in blood supply to the limb may lead to hypertrophy (Holman, 1937). Both Reid (1925) and Horton (1934) considered that the increase in bone length in the presence of a congenital arteriovenous communication is caused by an increase in blood flow to the growing end of the bone before closure of the epiphyses. Horton (1934) showed by arteriography that when the bone was lengthened an arteriovenous fistula may be in close apposition to the epiphyseal line.

Servelle $(1945 ; 1947)$ has claimed that the overgrowth of bone in the Klippel-Trenaunay syndrome may be due to venous stasis. He has shown in many cases that the venous pressure is raised, and demonstrated by venography that the venous circulation may be obstructed by a congenital defect such as a fibrous band. He considers that symptomatic relief may follow removal of the obstruction.

\section{Summary}

A case is described of enlargement of both lower limbs associated with an extensive cutaneous naevus and varicose veins in a boy aged seven years.

This patient exhibited the three features of the Klippel-Trenaunay syndrome: hypertrophy, naevus, and varicose veins. His condition was unusual in that both lower limbs were affected. It is also of interest that his mother developed varicose veins at an early age, which have proved intractable to treatment.

There was little evidence in favour of there being a congenital arteriovenous communication in either lower limb. No thrills or bruits were detected. The blood pressure in both lower limbs was the same and not abnormally raised. There was no cardiac enlargement. There was no bradycardiac response on occlusion of each femoral artery. The oxygen content of the venous blood from the right lower limb was normal. An arteriogram showed no evidence of an abnormal arteriovenous communication in either limb.

I have to thank Dr. T. Colver and Mr. Wilfred Hynes for permission to publish this case and for their encouragement. I am indebted to Mr. Clifford Jones and Mr. D. H. Randall for performing the arteriograms, to Dr. A. G. Macgregor for the oxygen estimations, and to Dr. T. Lodge for permission to reproduce $\mathrm{x}$-ray films.

\section{REFERENCES}

Adams, J. (1858). Lancet, 2, 140.

Beatty, C. C. (1927). Proc. R. Soc. Med., 20, 532. Blumgart, H. L., and Ernstene, A. C. (1932). Arch. intern. Med., 49, 599.

Branham, H. H. (1890). Int. J. Surg., 3, 250.

Cagiati, L. (1907). Dtsch. Z. Nervenheilk, 32, 282. 
Downing, J. G. (1933). Arch. Derm. Syph., Chicago, 28, Parkes Weber, F. (1907). Brit. J. Derm. Syph., 19, 231. 752.

East, T. (1932). Proc. R. Soc. Med., 25, 151.

Friedberg, H. (1867). Virchow Arch., 40, 353.

Freund, E. (1936). Arch. Surg., Chicago, 33, 113.

Gougerot, H., and Filliol, L. (1929). Arch. derm-syph., Paris, 1, 404.

Gray, A. M. H. (1928). Proc. R. Soc. Med., 21, 1431.

Holman, E. (1937). 'Arteriovenous Aneurysm.' New York, p. 39.

Horton, B. T. (1933). Proc. Mayo Clinic, 8, 189. (1934). Ibid., 9, 460.

Klippel, M., and Trenaunay, P. (1900). Arch. gén. Méd., $185,641$.

Lian, C., and Alhomme, P. (1945). Arch. Mal. Coeur., 38, 176.

Lewis, D. De Witt (1930). Lancet, 2, 621 and 680.

Louis -Bar, D., and Legros, J. (1946-47). Confin. neurol., Basel, 7, 245.

McGuire, J. (1935). Amer. Heart J., 10, 360.

Nicoladoni, C. (1875). Arch. klin. Chir., 18, 252.

- (1918). Brit. J. Child. Dis., 15, 13.

(1947). 'Rare Diseases and some Debatable Subjects.' 2nd Ed. London, p. 58.

Paterson, D., and Wyllie, W. G. (1925). Brit. J. Child. Dis., 22, 36.

Pemberton, J. de J., and Saint, J. H. (1928). Surg. Gynec. Obstet., 46, 470.

Reichenheim, P. P. (1943). St. Bart's Hosp. J. Wartime Series, 4, 53.

Reid, M. R. (1925). Arch. Surg., Chicago, 10, 601 and 996. Ibid., 11, 25 and 237.

_, and McGuire, J. (1938). Ann. Surg., 108, 643.

Trélat, U., and Monod., A. (1869). Arch. gén. Méd., 13, 536 and 676.

Servelle, M. (1945). Progr. méd. Paris, 53, 353. (1947). Arch. Mal. Coeur., 40, 125.

Ward, C. E., and Horton, B. T. (1940). J. Pediat., $16,746$.

Van Bogaert, A., and Kegels, C. (1947). Arch. Mal. Coeur, 40, 93. 